\title{
Long Term Skeletal Changes in a Young Woman Treated with Isotretinoin
}

\author{
Mónica Ibáñez Barceló ${ }^{*}$, Antonia Teresa Vila Mas², Ana Estremera Rodrigo ${ }^{3}$, Antonio Juan Mas ${ }^{1}$ \\ 'Rheumatology Department, Hospital Son Llàtzer, Palma de Mallorca, Spain. \\ ${ }^{2}$ Dermatology Department, Hospital Son Llàtzer, Palma de Mallorca, Spain. \\ ${ }^{3}$ Radiology Department, Hospital Son Llàtzer, Palma de Mallorca, Spain.
}

Article Info

\section{Article Notes}

Received: January 18,2020

Accepted: March 10, 2021

\section{*Correspondence:}

*Dr. Mónica Ibáñez Barceló, Rheumatology Department, Hospital Son Llàtzer, Palma de Mallorca, Spain; Email: mibanez@hsll.es.

${ }^{\oplus} 2021$ Barceló MI. This article is distributed under the terms of the Creative Commons Attribution 4.0 International License.

\section{Keywords:}

Diffuse idiopathic skeletal hyperostosis Isotretinoin

\section{Introduction}

Isotretinoin is an oral synthetic vitamin A medication used as a treatment for acne since 1982. Although isotretinoin use is very common in daily practice, there are still controversies involving isotretinoin and its long-term effects on the skeletal system: musculoskeletal pain, periosteal thickening, "retinoid hyperostosis", premature epiphyseal closure in children, osteoporosis, extraspinal tendon and ligament calcification, ossification of the posterior longitudinal ligament or effects on vitamin D metabolism ${ }^{1-15}$.

In this article we would like to focus in one of them: "retinoid hyperostosis". It was described in 1983 by Pittsley and Yoder ${ }^{1}$ and interestingly, appears at younger ages than patients with diffuse idiopathic skeletal hyperostosis (DISH) and mainly in the cervical spine and feet ${ }^{5-7}$.

\section{Case report}

Previously, we have described the case of a 36 years old woman with severe acne treated with isotretinoin since she was 25 years old $^{16}$. Although she referred cervical pain, the presence of DISH at cervical spine, made us look for the presence of findings in other typical DISH locations, such as the dorsal spine, calcaneus or pelvis (figures 1 to 3 ).

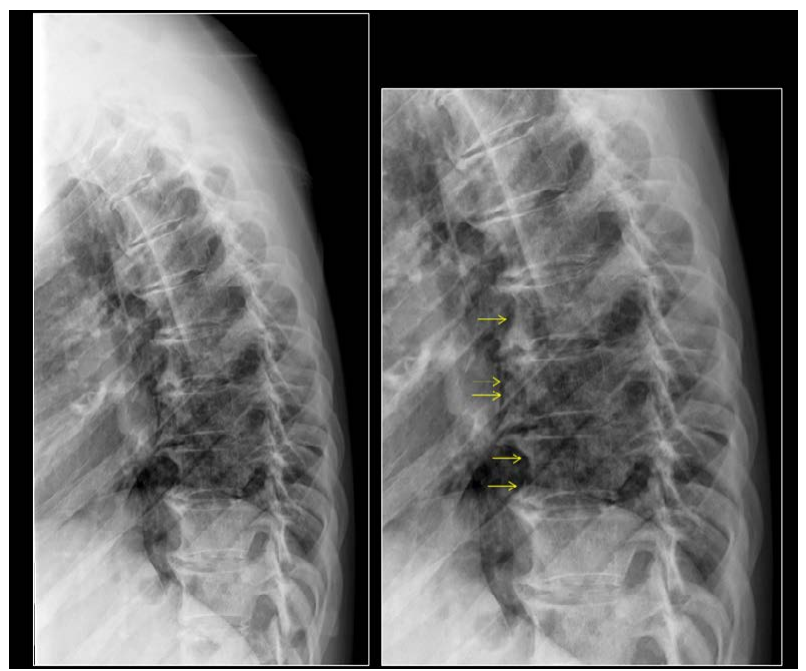

Figure 1: Dorsal Spine: lateral view of the dorsal spine showing ossification in the anterior longitudinal ligament (arrows shows abnormal density along the anterior aspect of vertebral bodies). 


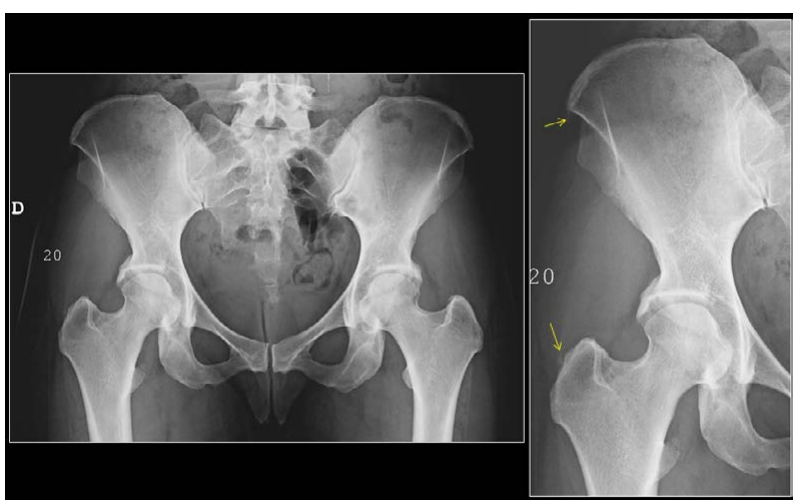

Figure 2: X-ray Pelvis: sacroiliac joints without abnormalities, mild enthesopathy at the iliac crests and at greater right trochanter (arrows).

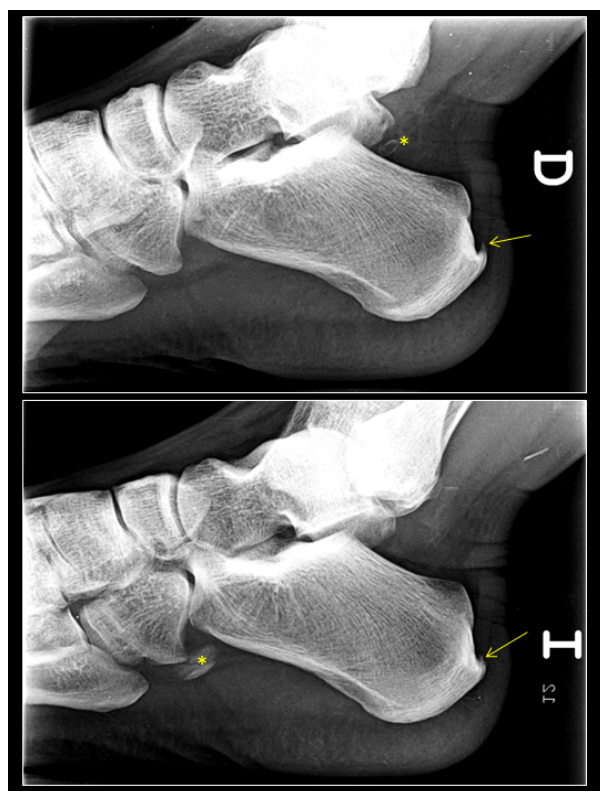

Figure 3: Signs of enthesitis at both Achilles tendon insertions (arrows). Accesory bones (asterisks).

Unfortunately, we can't confirm the cumulative dose because the patient was visited in our hospital for the third course of isotretinoin.

Due to chronic cervical pain, a cervical spine X-ray was done 6 years later, with no regression of the of ossification of the anterior longitudinal ligament. X-rays of the other locations were not performed because she didn't refer pain or restriction of movement.

\section{Discussion}

DISH or senile ankylosing hyperostosis was described by Forestier and Rotes-Querol in $1950{ }^{17}$. It is characterized by calcifications and ossifications of the entheses, affecting mainly the spine and peripheral sites. It is commonly seen in people older than 50 years old, preferentially in men with cardiovascular risk factors ${ }^{18-19}$. Most of them are asymptomatic.
Spinal DISH, with calcification of the anterior longitudinal ligament, is predominantly observed at the dorsal spine, although the cervical and lumbar spine can also be affected with progression of the disease ${ }^{20}$. DISH at the cervical spine can cause dysphagia and it is important to prevent complications in patients undergoing endotracheal intubation or upper gastrointestinal endoscopy ${ }^{21}$.

Peripheral involvement includes proliferation at entheseal sites specially in the pelvis (iliac crests, ischial tuberosities, pubis, lateral acetabulum and greater and lesser trochanters) and feet (insertion of the fascia plantar or the Achilles tendon).

In patients under treatment with isotretinoin, the standard regimen consists of achieving a cumulative dose of $120-150 \mathrm{mg} / \mathrm{kg}$. The current trend is to indicate low doses (20-30 mg per day) for longer periods of time, with the aim of minimizing mucocutaneous adverse effects and long-term side effects on the bone, as well as increasing patient compliance. However, at recommended doses, more than $20 \%$ of patients experience a relapse within two years that requires retrial ${ }^{22-23}$.

The most common adverse effects are dryness of lips, skin and eyes, followed by headaches, joint and muscle aches, hypertriglyceridemia and transaminase elevation ${ }^{23}$.

This case report has several limitations: we don't have pretherapy X-rays, and we can't confirm the cumulative dose.

The question suggested by other authors, like Ling TC in $2001^{4}$, for the need of radiological monitoring at baseline or during therapy, especially in patients taking high doses of isotretinoin for long periods, is still debated 20 years later.

\section{Conclusions}

In patients receiving isotretinoin, arthralgias are common and normally transitory. However, long-term effects on the skeletal system still remain controversial.

Informed consent was obtained from the patient for the publication of this report.

\section{References}

1. Pittsley RA, Yoder FW. Retinoid hyperostosis. Skeletal toxicity associated with long-term administration of 13-cis-retinoic acid for refractory ichthyosis. N Engl J Med 1983; 308: 1012-4.

2. Montag $\mathrm{M}$, Reiser $\mathrm{M}, \mathrm{Hamm} \mathrm{H}$, et al. Skelettveränderungen nach Langzeitbehandlung mit Retinoiden [Skeletal changes following longterm treatment with retinoids]. Radiologe. 1988 Jul; 28(7): 320-5. German. PMID: 3045876.

3. Zhao S, Goodson NJ. Diffuse idiopathic skeletal hyperostosis and isotretinoin in cystic acne. BMJ Case Rep. 2015 Jun 23; 2015. pii: bcr2015209775.

4. Ling TC, Parkin G, Islam J, et al. What is the cumulative effect of long-term, low-dose isotretinoin on the development of DISH? Br J Dermatol 2001; 144(3): 630-2. 
5. Graf SW, Whittle SL. Isotretinoin-induced skeletal hyperostosis. Springerplus. 2014 Nov 27;3:698. doi: 10.1186/2193-1801-3-698. PMID: 26034688; PMCID: PMC4447744.

6. Kilcoyne RF, Cope R, Cunningham W, et al. Minimal spinal hyperostosis with low-dose isotretinoin therapy. Invest Radiol 1986; 21(1): 41-4.

7. Pennes DR, Martel W, Ellis CN, et al. Evolution of skeletal hyperostoses caused by 13-cis-retinoic acid therapy. AJR Am J Roentgenol 1988; 151(5): 967-73.

8. Tangrea JA, Kilcoyne RF, Taylor PR, et al. Skeletal hyperostosis in patients receiving chronic, very-low-dose isotretinoin. Arch Dermatol1992; 128(7): 921-5.

9. Blasiak RC, Stamey CR, Burkhart CN, et al. High-dose isotretinoin treatment and the rate of retrial, relapse, and adverse effects in patients with acne vulgaris.JAMA Dermatol. 2013; 149: 1392-8.

10. Ertugrul DT, Karadag AS, Tutal E, et al. Therapeutic hotline. Does isotretinoin have effect on vitamin D physiology and bone metabolism in acne patients? Dermatol Ther. 2011 Mar-Apr; 24(2): 291-5.

11. 11.Pennes DR, Martel W, Ellis CN. Retinoid-induced ossification of the posterior longitudinal ligament. Skeletal Radiol. 1985; 14(3): 191-3. doi: 10.1007/BF00355561. PMID: 3933122.

12. Lamb RC, Lang J, Terron-Kwiatowski A, et al. Avascular necrosis of the hip and diffuse idiopathic skeletal hyperostosis during long-term isotretinoin treatment of epidermolytic ichthyosis due to a nove deletion mutation in KRT10. Br J Dermatol. 2014 Oct; 171(4): 913-5.

13. Tekin NS, Ozdolap S, Sarikaya S, et al. Bone mineral density and bone turnover markers in patients receiving a single course of isotretinoin for nodulocystic acne. Int J Dermatol. 2008 Jun; 47(6): 622-5. doi: 10.1111/j.1365-4632.2008.03534.x. PMID: 18477161.

14. DiGiovanna JJ. Isotretinoin effects on bone. J Am Acad Dermatol. 2001 Nov; 45(5): S176-82. doi: 10.1067/mjd.2001.113721. PMID: 11606950
15. Kaplan G, Haettich B. Rheumatological symptoms due to retinoids. Baillieres Clin Rheumatol. 1991 Apr; 5(1): 77-97. doi: 10.1016/ s0950-3579(05)80297-3. PMID: 2070429.

16. Ibáñez Barceló M, Estremera Rodrigo A, Ros Vilamajó I, et al Diffuse Idiopathic Skeletal Hyperostosis in a Young Woman Treated With Isotretinoin. Reumatol Clin. 2020 Oct. doi: 10.1016/j. reuma.2020.09.005.

17. Forestier J, Rotes-Querol L. Senile ankylosing hyperostosis of the spine. Ann Rheum Dis. 1950 Dec; 9(4): 321-30

18. Westerveld LA, van Ufford HM, Verlaan JJ, et al. The prevalence of diffuse idiopathic skeletal hyperostosis in an outpatient population in The Netherlands. J Rheumatol. 2008 Aug; 35(8): 1635-8.

19. Mader R, Novofestovski I, Adawi M, et al. Metabolic syndrome and cardiovascular risk in patients with diffuse idiopathic skeletal hiperostosis. Semin Arthritis Rheum. 2009; 38(5): 361-5.

20. Resnick D. Diffuse idiopathic skeletal hiperostosis. In: Resnick D, ed. Diagnosis of bone and joint disorders, 4th ed. Philadelphia,PA: Saunders, 2002: 1476-1503.

21. Olivieri I, D’Angelo S, Palazzi C, et al. Diffuse idiopathic skeletal hyperostosis: differentiation from ankylosing spondylitis. Curr Rheumatol Rep. 2009 Oct; 11(5): 321-8.

22. Mader R, Sarzi-Puttini P, Atzeni F, et al. Extraspinal manifestations of diffuse idiopathic skeletal hyperostosis. Rheumatology (Oxford) 2009 Dec; 48(12): 1478-81

23. Landis MN. Optimizing Isotretinoin Treatment of Acne: Update on Current Recommendations for Monitoring, Dosing, Safety, Adverse Effects, Compliance, and Outcomes. Am J Clin Dermatol. 2020 Jun; 21(3): 411-9. 